\title{
Antimicrobial and Catalytic Activities of Green Synthesized Silver Nanoparticles Using Bay Laurel (Laurus nobilis) Leaves Extract
}

\author{
Abdulaziz Yahya Al-Ghamdi \\ Department of Biology, Faculty of Science, Al-Baha University, KSA \\ Email: dr-azizghamdi@hotmail.com
}

How to cite this paper: Al-Ghamdi, A.Y. (2019) Antimicrobial and Catalytic Activities of Green Synthesized Silver Nanoparticles Using Bay Laurel (Laurus nobilis) Leaves Extract. Journal of Biomaterials and Nanobiotechnology, 10, 26-39.

https://doi.org/10.4236/jbnb.2019.101003

Received: December 10, 2018

Accepted: January 27, 2019

Published: January 30, 2019

Copyright $\odot 2019$ by author(s) and Scientific Research Publishing Inc. This work is licensed under the Creative Commons Attribution International License (CC BY 4.0).

http://creativecommons.org/licenses/by/4.0/

\begin{abstract}
In this study, bay laurel extract (BLE) used as a reducing and capping agent for the synthesis of silver nanoparticles (AgNPs). The green-prepared AgNPs investigated using UV-visible spectroscopy, Fourier-transform infrared spectroscopy (FTIR), X-ray powder diffraction (XRD), Scanning Electron Microscopy with Energy Dispersive X-ray (SEM-EDX) and Transmission electron microscopy (TEM). Formation of AgNPs monitored at ambient temperature by a change in color from the starting solution to dark brown. Green synthesis AgNps were investigated for antimicrobial activity. The microorganisms employed were E. coli, $K$. pneumoniae, B. cereus, S. aureus, C. lbicans and Aspergillus. The susceptibility of microorganisms against the six AgNPs solutions was determined using the disk diffusion method. The catalytic activity of the prepared AgNPs (sample, d) for basic brown 1 dye was investigated. The results showed the characteristic surface plasmon resonance peak of the AgNPs appeared at approximately $415-440 \mathrm{~nm}$. XRD revealed peaks at 38.2, $44.16,64.24$ and $77.22 \Theta$, and the intensity of these peaks enhanced when using microwave curing compared to ambient temperature. SEM and TEM results showed that the silver nano particles have a spherical shape and the particle size for samples is less than $34 \mathrm{~nm}$. FTIR spectroscopy measurements showed the binding of organic compounds on the surface of the silver nanoparticles. Highest antibacterial activity was enhanced with increasing of AgNPs dose and with increasing of extract ration against most of microorganisms except. Removal of basic brown 1 dye by the prepared AgNPs indicated complete dye removal after $8 \mathrm{~h}$.
\end{abstract}

\section{Keywords}

Green Synthesis, AgNPs, Removal Basic Brown 1, Biological Activity 


\section{Introduction}

Metal nanoparticles have unique physical and chemical properties that are mainly different from those of bulk materials, making them a target of study by many researchers in recent years [1]. Silver nanoparticles have unique properties due to their surface area and particle size, making them used in many varied applications [2]. Solar energy systems, optics, catalytic and antibacterial capacities are main application fields of AgNPs [3]. The antibacterial inhibitions of silver nanoparticles recently are studied. Silver nanoparticles (AgNPs) display effective antimicrobial capacity against both gram-positive and gram-negative bacterial strains. The uses of toxic and hazardous chemicals, in addition to high cost and power consumption are the main drawbacks of methods used in the preparation of silver nanoparticles [4]. AgNPs were synthesized using a variety of plant extracts as reducing and stabilizing agents such as Ziziphus Jujuba leaf [5], Megaphrynium macrostachyum leaf [6], Myrmecodia pendan (Sarang Semut plant) [7], Neem (Azadirachta indica) leaves [8], Bergenia ciliata [9], sulfated polysaccharide extract from Sargassum siliquosum, a brown alga [10], Eucalyptus oleosa [11], Annona squamosa L. [12], Pistacia atlantica [13], Pongamia pinnata [14], the cell free filtrate of marine sediment fungal species from the Southern peninsular coastal region of India [15], isoamyl acetate isolated from Annona squamosa [16], Eucalyptus camaldulensis [17], cellulose extract and sucrose [18], Chomelia asiatica plant leaves [19], aqueous Raphanus sativus root [20], chamomile [21], Commiphora caudata leaves [22], Staphylococcus epidermidis [23], and L-cysteine [24]. Furthermore, extract of Manilkara zapota (L.) seeds [25], Canna edulis Ker-Gawl [26] and aqueous extract of turmeric powder [27] were used to enhance the green synthesis of AgNPs.

The leaves of the bay laurel plant (Laurus nobilis) are widely used as a spice in foods and for production of its essential oil [27]. The bay laurel tree grows in the Mediterranean area and the southeast part of Europe [28]. The essential oil of bay laurel contains many active materials such as terpineol and cineol [29]. It has shown antimicrobial and antifungal characteristics as well as hypoglycaemic and antiulcerogenic properties [30] [31].

The current study was designed for green synthesis of AgNPs from silver nitrate solution using an aqueous extract of bay laurel leaves. In addition, the antimicrobial activity of synthesized AgNPs was examined. The ability of the prepared AgNPs to remove basic brown 1 dye from aqueous solution was studied.

\section{Materials and Methods}

Healthy leaves of bay laurel collected from a local market, Figure 1(a). After washing the leaves, they dried in the shade and ground to obtain powder. Approximately $100 \mathrm{~g}$ of the leaf powder added to $500 \mathrm{ml}$ of distilled water in a 1000 $\mathrm{ml}$ Erlenmeyer flask. The mixture boiled for $10 \mathrm{~min}$ and cooled to room temperature.

Then, the extract was filtered, and the collected filtrate was stored at $4^{\circ} \mathrm{C}$ for further use. $\mathrm{AgNO}_{3}$ 99.9\% was purchased from Sigma-Aldrich, Cairo, Egypt. 


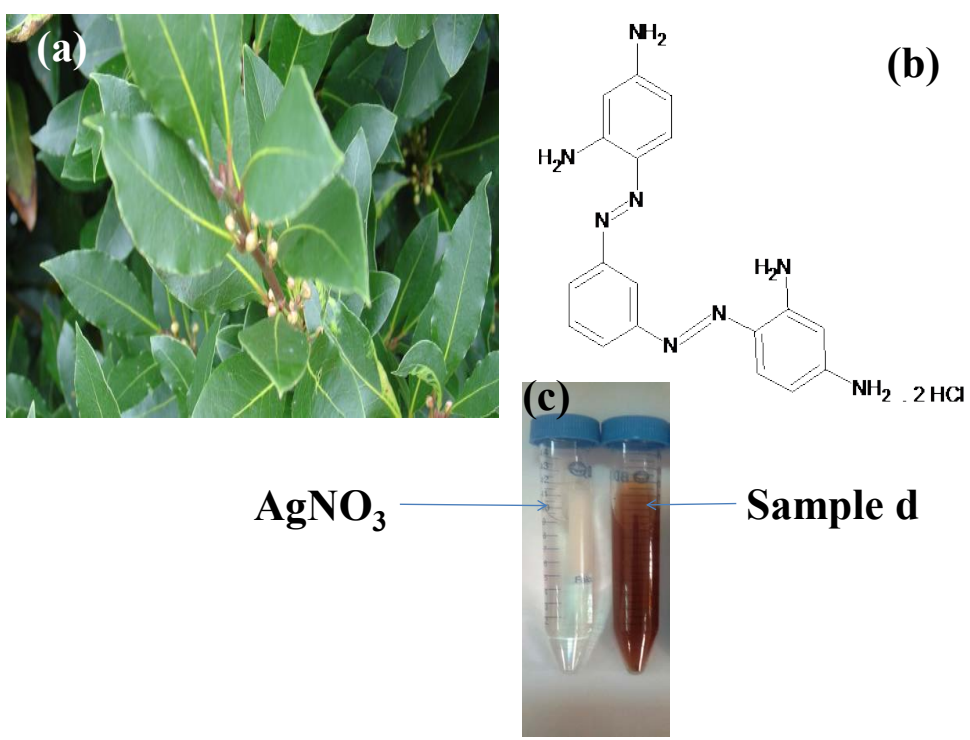

Figure 1. (a) Bay laurel leaves, (b) Basic brown 1 dye, (c) Prepared AgNPs.

Table 1 shows the different substitution ratios (R) of silver nitrate solution with extract that used for green synthesis of AgNPs. A $20 \mathrm{mM}$ solution of Ag$\mathrm{NO}_{3}$ was prepared for production of AgNPs. Green reduction of $\mathrm{Ag}^{+}$monitored using visual observation and UV-visible spectroscopy.

Bacterial strains were isolated from food samples, which included E-Coli and Klebsilla (gram negative); Bacillus Cereus and Staph Aureus (gram positive); Candida (yeast) and Aspirigullus (mold). The strains were kept at $4^{\circ} \mathrm{C}$ on agar slant and sub cultured at $37^{\circ} \mathrm{C}$ for $24 \mathrm{~h}$ on nutrient agar (oxoid UK) before any susceptibility test.

The reduction of silver ions into silver particles monitored by UV-visible spectroscopy (SHIMADZU MODELUV 1800, Japan) at a wavelength of 350 $700 \mathrm{~nm}$. A diffractometer XRD thin film PANalytical X pert PRO, Cu target, wave length $1.54 \mathrm{~A}^{\circ}, 45 \mathrm{kV}, 40 \mathrm{~mA}$ made in Holland was used for determining the crystallinity of prepared AgNPs. Scanning electron microscopy (SEM) examination was performed using JEOL JSM 6360 DLA, Japan, at $30 \mathrm{kV}$, and the SEM-EDX analysis was performed by FEI Company, Quanta FEG250, Holland. Transmission electron microscopy image were taken using a Hitachi, H-800 TEM. TEM samples were prepared by placing drops of aqueous dispersion of AgNPs in distilled water on 200 mesh carbon coated copper grids and dried at ambient conditions for 10 to $12 \mathrm{~h}$. The FT-IR spectra of the products recorded on a JASCO Asia Portal-FT/IR-6300 Spectrometer using the KBr pellet method.

The antimicrobial activity of AgNPs was investigated by the disk diffusion method. The pure cultures of each strain were swabbed uniformly on the individual plates using sterile cotton at $35^{\circ} \mathrm{C}$ on a rotary shaker at $200 \mathrm{RPM}$. Three disks were made in each plate, and 10, 20 and $50 \mu \mathrm{L}$ of the sample of nanoparticle solution were poured using micropipettes onto the disks on all plates. The zones of inhibition (ZoI) around the discs were measured after incubation period. 
Table 1. Different concentration of silver nitrate and BLE extract used for green synthesis of AgNPs.

\begin{tabular}{ccccc}
\hline Code & $\mathrm{AgNO}_{3}, 5 \mathrm{mM}, \mathrm{ml}$ & BLE, ml & Ratio & Temperature \\
\hline a & 90 & 10 & 10 & ambient \\
b & 80 & 20 & 20 & ambient \\
c & 70 & 30 & 30 & ambient \\
d & 60 & 40 & 40 & ambient \\
\hline
\end{tabular}

The catalytic activity of the prepared AgNPs (sample, d) for basic brown 1 (BB1), Figure 1(b), in solution was studied. All photocatalytic experiments were carried out outdoors with direct sunlight as the main source of light. $0.1,0.2,0.3$, 0.4 and $0.5 \mathrm{ml}$ of AgNPs added to $50 \mathrm{ml}$ of BB1 solution ( $100 \mathrm{mg} / \mathrm{l})$. A sample of dye solution without AgNPs was also investigated. The solution was stirred in the dark for $45 \mathrm{~min}$ to ensure that equilibrium of the working solution was reached prior to exposure under direct sun-light. The solutions were kept under direct sunlight while stirring. The absorption spectra of the solutions were checked after every 1, 2, 4 and $8 \mathrm{~h}$ using UV-visible spectrophotometry.

\section{Results and Discussion}

\subsection{Characterization of AgNPs}

Green reduction of $\mathrm{Ag}^{+}$by BLE was monitored by observing the color of silver solutions that changed from colorless, to yellow, brown and then reddish brown as evidence of silver ion reduction, Figure 1(c), increasing the silver nano particle concentration and changing the particle morphology. It was observed that the color started to change after $30 \mathrm{~min}$. and reached a maximum absorption capacity of UV after $180 \mathrm{~min}$. This period decreased with increasing the BLE content. In addition, the UV-Vis spectroscopy investigation of the prepared AgNPs showed that the size and shape of AgNPs influence the shape and position of the UV-Vis absorption peaks from plasmon resonance. The UV-Vis absorption spectra of the synthesized AgNPs at ambient temperatures with time intervals up to $3 \mathrm{~h}$ are shown in Figures 2(a)-(d). There no 150, 180 min data in $2 \mathrm{~d}$ because the absorption reached to maximum absorption capacity of UV after $120 \mathrm{~min}$.

The appearance of a strong peak at $437 \mathrm{~nm}$ indicated the formation of AgNPs that related to its surface plasmon resonance phenomena [32]. As shown in Figures 2(a)-(d), the absorbance value for AgNPs increased with an increase in BLE ratio and indicated a higher concentration of AgNPs produced, which was due to the availability of more reducing bio-molecules in BLE. The SPR peaks at a lower substitution of BLE 20:80 (v/v) were broad band whereas with a higher substitution ratio the SPR peaks became sharper and narrower. The intensity of this absorption band increased with time with a slight shift to $441 \mathrm{~nm}$. The peak intensity was enhanced and shifted from 437 to $411 \mathrm{~nm}$ with curing time and 


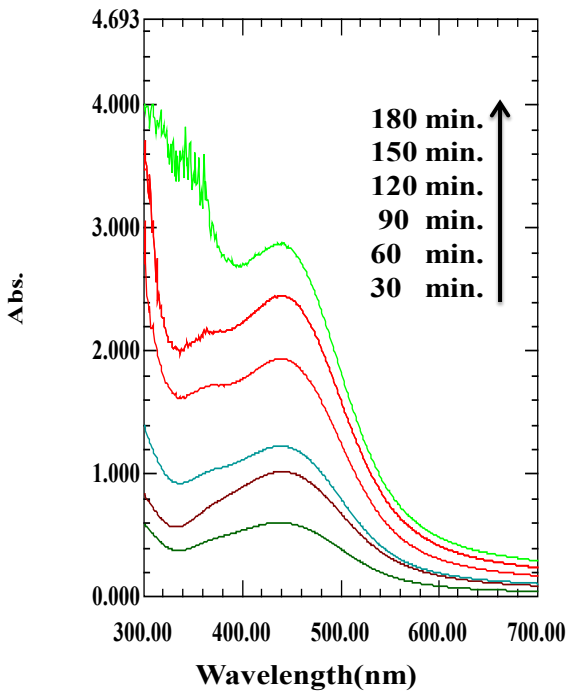

(a)

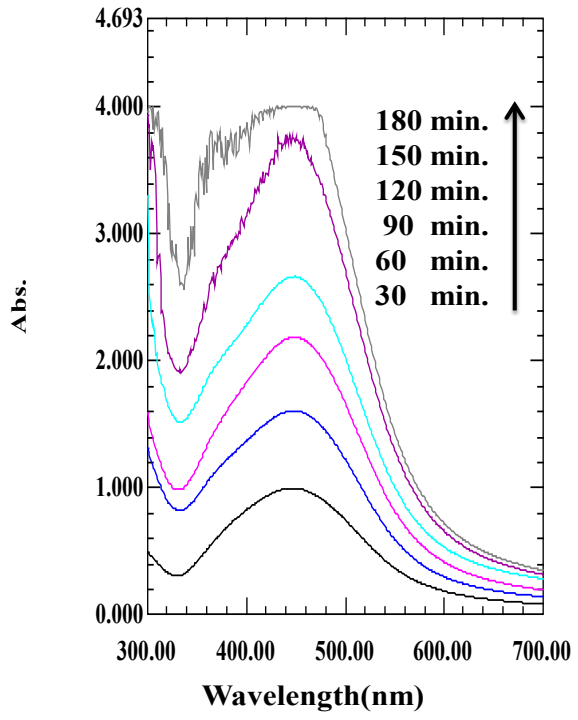

(c)

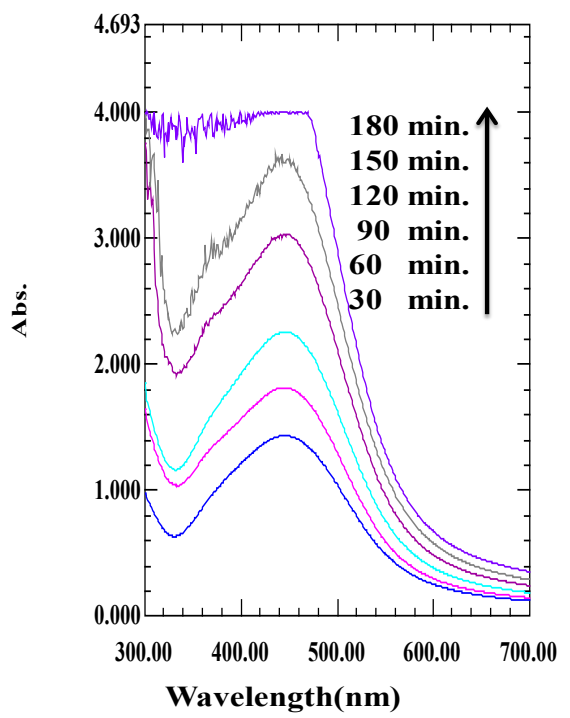

(b)

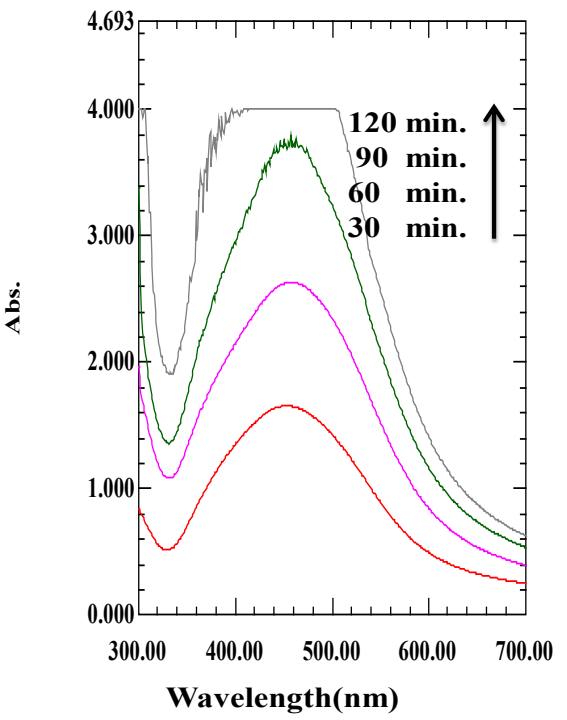

(d)

Figure 2. Absorption spectra of prepared AgNPs at ambient temperature (a) 10\%, (b) $20 \%$, (c) $20 \%$ and (d) $40 \%$ of BLE leaf extract.

increased the R-value indicating that the content of silver nanoparticles increased. The organic compounds in the BLE contain numerous functional groups that can interact with silver to form a complex. Furthermore, the cleavage of $\mathrm{C}-\mathrm{C}$ bonds of organic molecules released electrons required for the reduction of $\mathrm{Ag}$. When the complex compound $\mathrm{Ag}^{+-} \mathrm{BLE}$ was reduced to $\mathrm{Ag}^{0-} \mathrm{BLE}$, the organic molecules endow AgNPs with excellent dispersibility.

Figure 3 shows XRD patterns of the green synthesized AgNPs. The distinct diffraction bands at approximately 37.97, 44.29, 64.38 and $77.392 \Theta$ correspond to (111), (200), (220) and (311), respectively, were matched to planes of a face-centered cubic lattice of silver (ICSD No. 01-071-4613), which confirm the crystalline structure of prepared AgNPs. 


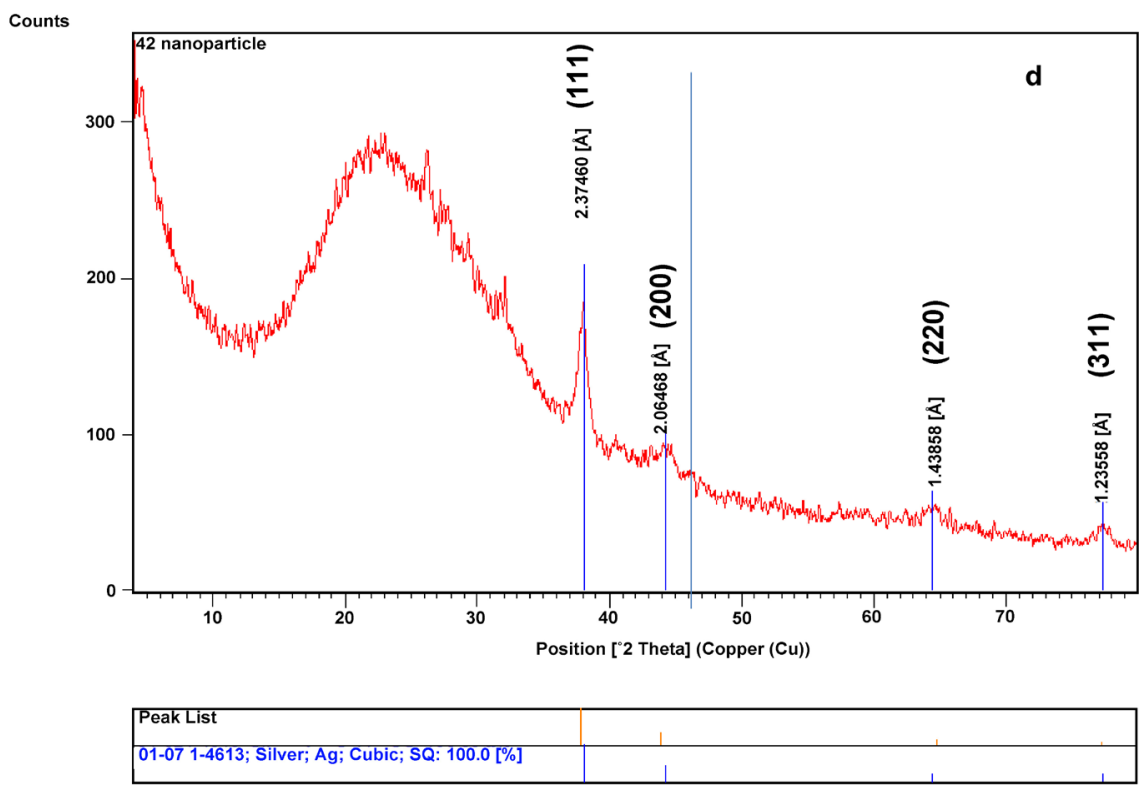

Figure 3. XRD patterns of synthesized AgNPs at ambient temperature (d) $40 \%$ of leaf extract.

The extra peaks near 22.5, 26.2, 29.2 and $32.02 \Theta$ are due to the presence of organic compounds on the surface of AgNPs. The intensity of the characteristic peaks of AgNPs increased with increasing $\mathrm{R}$ ratio indicating progression of the reduction process due to the availability of a suitable amount of bio reducer of $\mathrm{Ag}^{+}$. Additionally, the intensities of the characteristic peaks of AgNPs prepared using microwave curing were higher than that prepared at room temperature. These results indicate that using microwave curing enhances the bio-synthesis process of AgNPs. The intensity of the peak at the (111) plane was greater than the other peaks, suggesting that this plane was the predominant one. According to Scherrer's formula, the average sizes of AgNPs synthesized by leaf extracts at room temperature and using microwave curing are 22 and $28 \mathrm{~nm}$, respectively [18] [33]. The presence of organic compounds of BLE extract on the surface of the nanoparticles was investigated using FTIR.

The FTIR spectra of silver nanoparticles prepared with 40:60 (v/v) leaf extract: $\mathrm{Ag}^{+}$(d) at ambient is shown in Figure 4. The band at $3432 \mathrm{~cm}^{-1}$ is attributed to the hydroxyl group of organic compounds, the small bands appearing at 2927 and $2852 \mathrm{~cm}^{-1}$ may be due to $\mathrm{C}-\mathrm{H}$ stretching of vibration of the $-\mathrm{CH}_{2}$ group from the aliphatic chains, and a relatively strong band can be noted at $2065 \mathrm{~cm}^{-1}$ due to $\mathrm{CN}$ stretching vibration [34]. Additionally, the band at $1635 \mathrm{~cm}^{-1}$ is related to stretching of the carbonyl groups and bands at $1384 \mathrm{~cm}^{-1}$ and $1106 \mathrm{~cm}^{-1}$ related to the carboxylic groups. These absorption bands indicate the absorption of different organic compounds on the surface of the nanoparticles [35] [36] [37].

Figure 5 shows SEM images of the nanoparticles synthesized with 40:60 (v/v) BLE leaf extract: $\mathrm{Ag}^{+}(\mathrm{d})$ at ambient. Mostly spherical and near spherical shapes were observed for AgNPs in the 20 - $40 \mathrm{~nm}$ size range. 


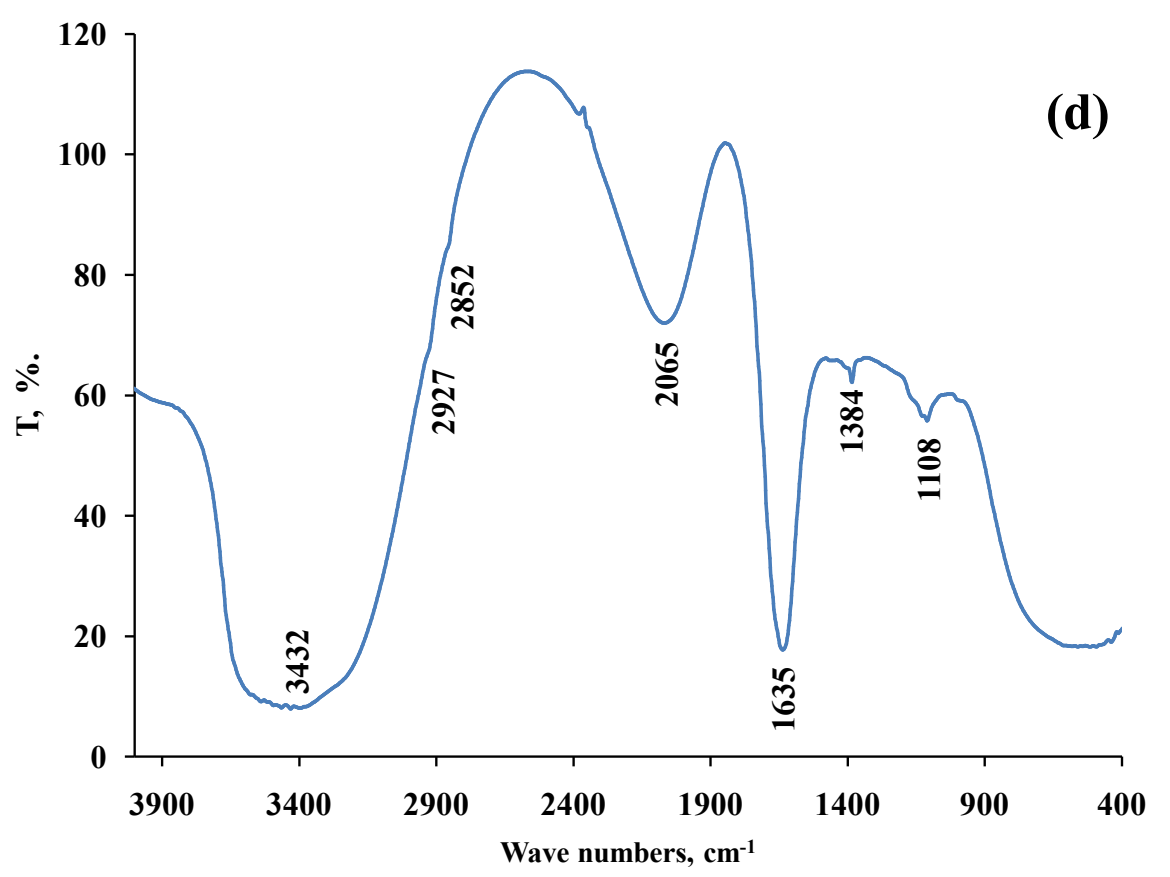

Figure 4. FTIR spectra of synthesized AgNPs at ambient temperature (d) $40 \%$ of leaf extract.

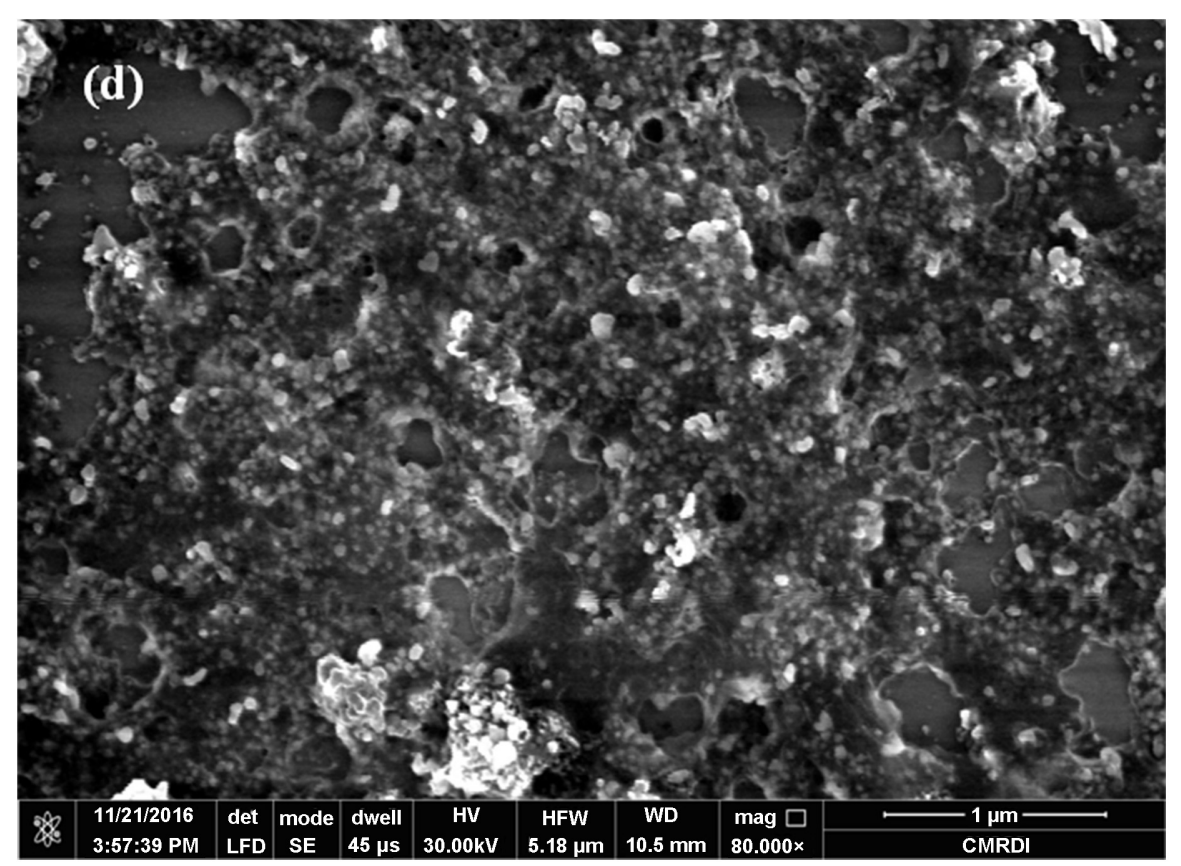

Figure 5. (a) FESEM micrograph of synthesized AgNPs at ambient temperature (d) $40 \%$ of leaf extract.

TEM analysis gives actual information about the morphology of the surface of the AgNPs. TEM images of the prepared AgNPs with different magnifications are shown in Figures 6(a)-(c). They clearly show the formation of the best AgNPs with spherical and oval shapes in the size range of $17-34 \mathrm{~nm}$. These perfect particle sizes with various shapes of AgNPs may be related to different 


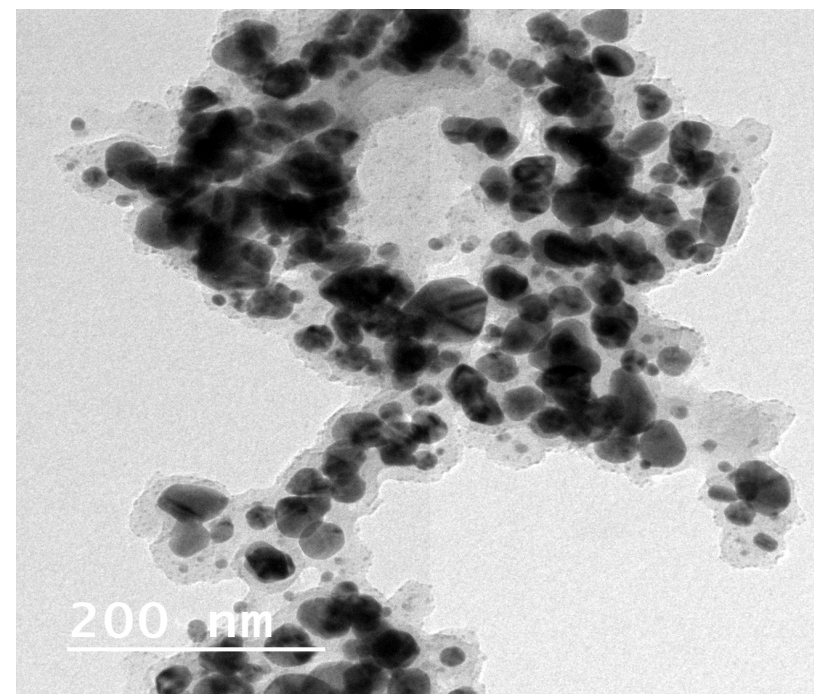

(a)

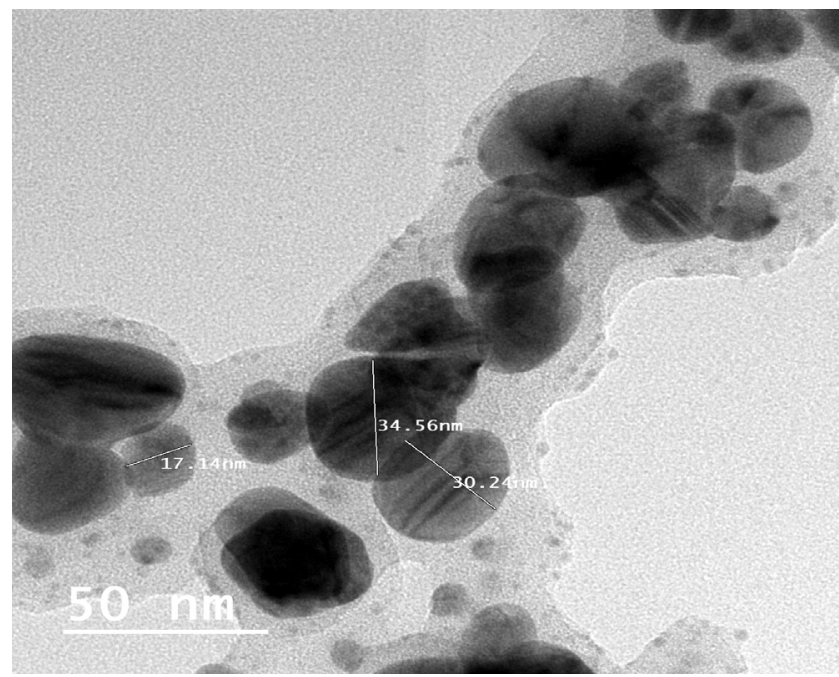

(c)

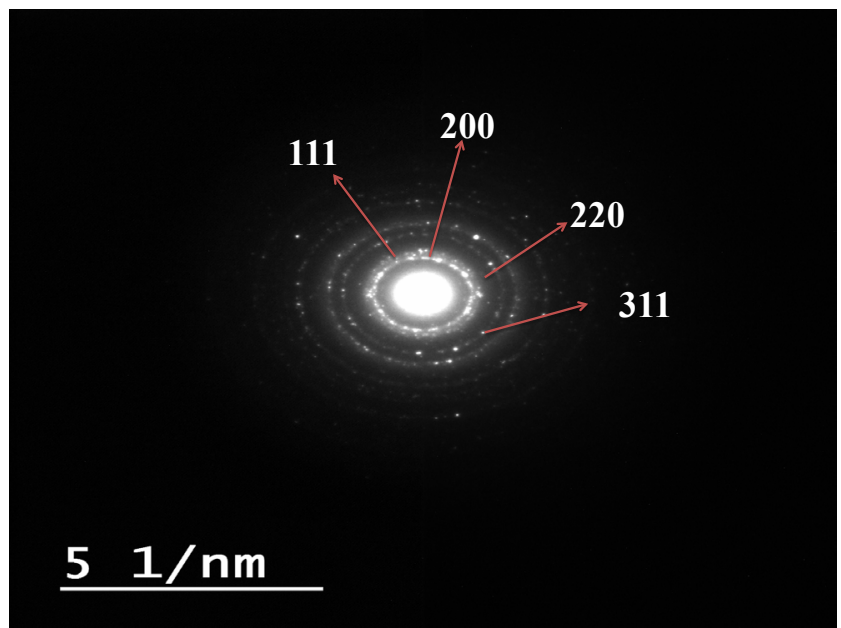

(e)

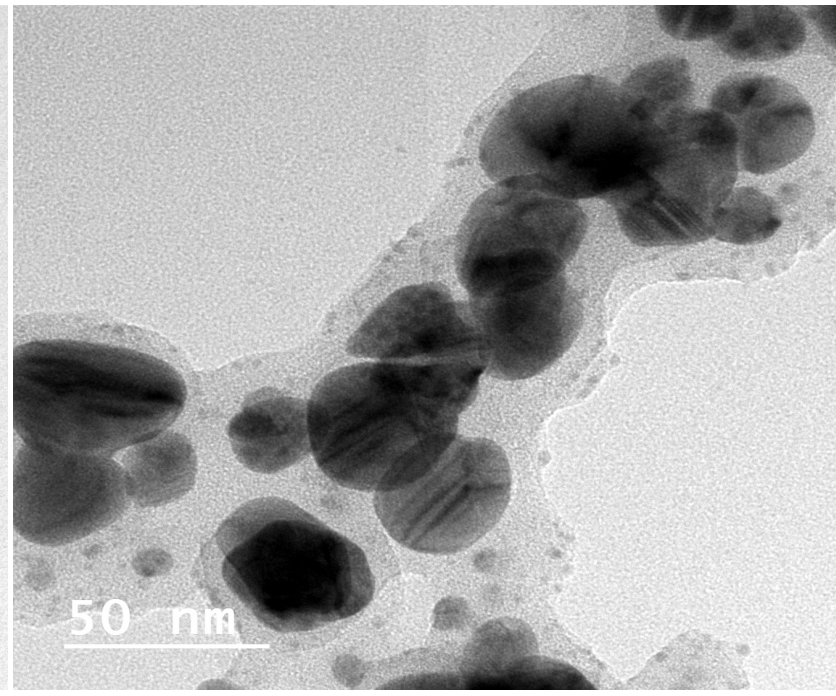

(b)

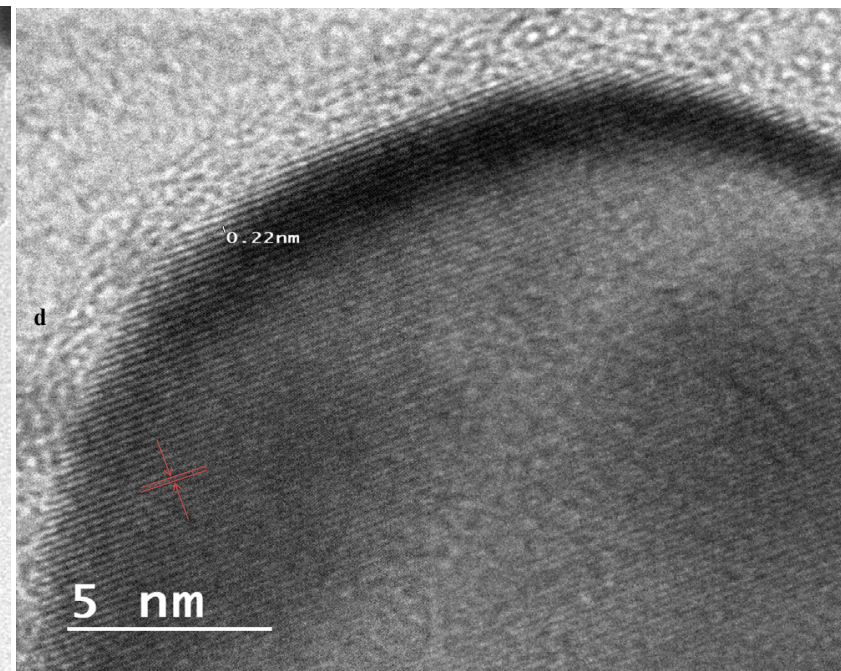

(d)

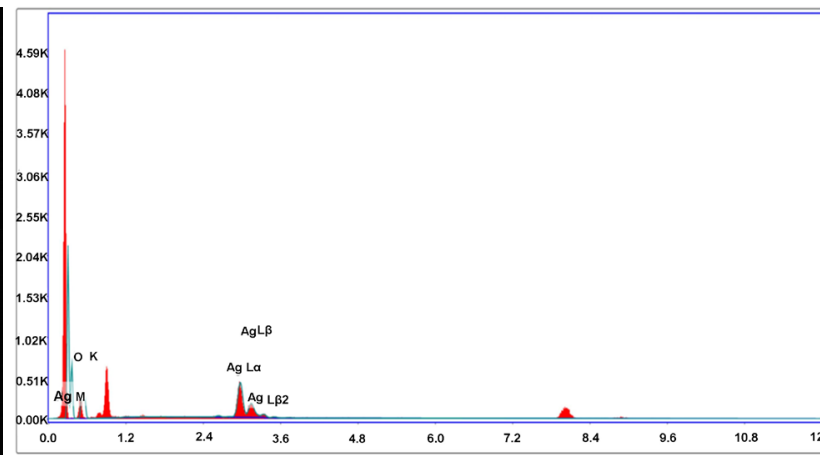

Element Weight \% Atomic \% Net Int. Error \%

\begin{tabular}{|c|c|c|c|c|}
\hline OK & 50.74 & 87.41 & 47.02 & 12.74 \\
\hline Ag L & 49.26 & 12.59 & 135.99 & 5.53 \\
\hline
\end{tabular}

(f)

Figure 6. (a)-(d) HRTEM images of synthesized AgNPs at ambient temperature (d) $40 \%$ of leaf extract, (e) SADE image, (f) EDX Spectrum. 
components of the plant extract [38]. An HRTEM image of AgNPs is shown in Figure $6(\mathrm{~d})$. It clearly shows a lattice spacing of $0.21 \mathrm{~nm}$ related to the (111) plane of Ag that matches with the XRD pattern. The polycrystalline nature of prepared silver nano particles was confirmed by SAED, Figure 6(e), as the FCC structure of silver [39]. Furthermore, EDX analysis confirmed the presence of silver as a single element.

\subsection{Antimicrobial Activity of Green Prepared AgNPs}

Antibacterial activities of the prepared AgNPs using extract of Laurus nobilis against the tested organisms are shown in Table 2 and Figure 7. All the AgNPs samples tested showed antibacterial activity, however, the BLE extract differ in its activities against the micro-organisms tested. As seen in Table 2, the inhibition zone area increased with a higher dose of AgNPs from 25 to $200 \mu \mathrm{ml}$. Highest antibacterial activity was observed with increasing ratio of plant extract (d, $40 \%$ ) against E. Coli, K. Pneumoniae and B. Cereus. This is clearly attributed to antimicrobial efficiency of AgNPs, and not to the organic compounds in the extract. The mechanism of AgNPs as an antimicrobial is not understood, but many studies suggest that it occurs through the interaction of silver nanoparticles with the DNA of microorganisms, forming free radicals and destructuring the cell walls [40] [41]. It is worth mentioning that the aqueous extract of BLE did not record any antibacterial effect against the same microorganisms. In addition, as show in Figure 7 ZOI decreased with increasing the ratio of BLE extract that attributed to the increasing in viscosity of media.

\subsection{Evaluation of Catalytic Activity of Green-Prepared Silver Nano-Particles}

The degradation process is dependent on the photocatalytic activity of AgNPs. Figure 8 (a) shows the photocatalytic degradation of BB 1 with different doses of green-prepared silver nanoparticles. It was observed that the degradation efficiency increased with increasing AgNPs dose. This attributed to increases in the number of active centres at the surface of biocatalyst (AgNPs) which allows more dye molecules to interact at the surface enhancing the degradation process.

Table 2. Antimicrobial activity of green synthesis AgNPs against different microorganisms.

\begin{tabular}{|c|c|c|c|c|c|c|c|c|c|c|c|c|c|c|}
\hline Sample & $\mathrm{b}$ & $c$ & d & $\mathrm{b}$ & c & $\mathrm{d}$ & $\mathrm{b}$ & c & $\mathrm{d}$ & $\mathrm{b}$ & c & $\mathrm{d}$ & \multicolumn{2}{|c|}{ Blank } \\
\hline Dose, $\mu \mathrm{L}$ & & 25 & & & 50 & & & 100 & & & 200 & & -ve ZOI & +ve ZOI \\
\hline Micro organism & \multicolumn{14}{|c|}{ Zone of inhibition* } \\
\hline E. Coli & 0 & 0 & 0 & 11.40 & 17.53 & 16.65 & 22.51 & 22.35 & 18.2 & 26.2 & 28.6 & 32.3 & 0 & 22.75 \\
\hline K. Pneumoniae & 11.55 & 12.61 & 13.05 & 22.7 & 20.12 & 21.4 & 22.52 & 16.92 & 20.11 & 34.17 & 23.07 & 25.19 & 0 & 20.61 \\
\hline B. Cereus & 0 & 12.37 & 12.61 & 17.72 & 17.26 & 16.25 & 20.34 & 26.64 & 24.93 & 23.34 & 26.86 & 27.17 & 0 & 25.5 \\
\hline S. Aureus & 0 & 12.57 & 11.68 & 15.1 & 18.29 & 18.64 & 18.17 & 16.47 & 17.36 & 21.56 & 26.93 & 20.87 & 0 & 27.44 \\
\hline C. Ibicans & 0 & 0 & 11.05 & 12.34 & 13.11 & 14.11 & 16.39 & 13.14 & 13.83 & 25.48 & 26.69 & 27.95 & 0 & 0 \\
\hline Aspergillus & 0 & 0 & 0 & 13.22 & 14.62 & 16.32 & 16.05 & 18.18 & 16.52 & 25.28 & 22.54 & 21.4 & 0 & 0 \\
\hline
\end{tabular}

${ }^{\star}$ Values are mean inhibition zone $(\mathrm{mm}) \pm$ S.D of three replicates. 


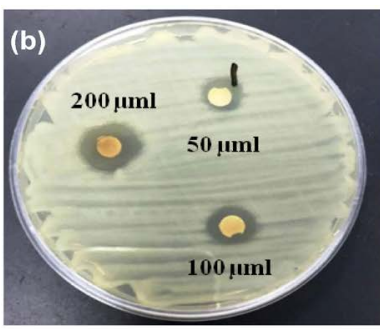

b

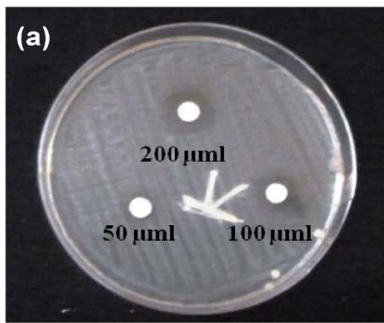

b

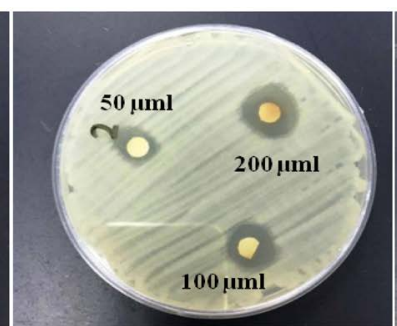

c

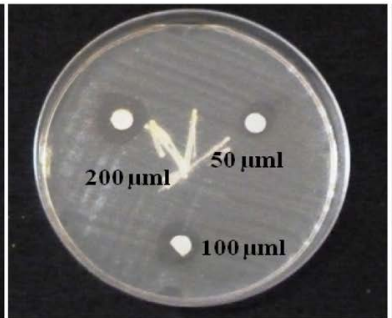

c
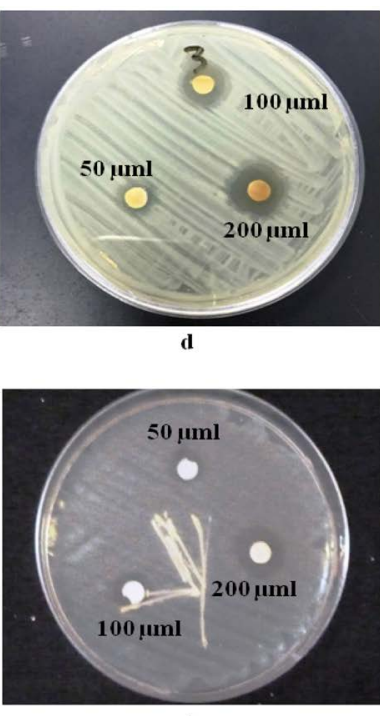

Figure 7. Antimicrobial activity of green synthesized Ag nanoparticles against (a) E. coli and (b) B. cereus.

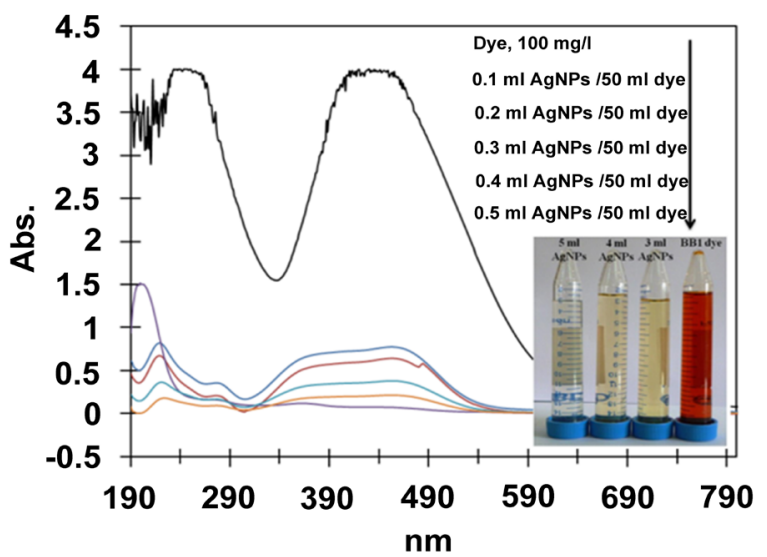

(a)

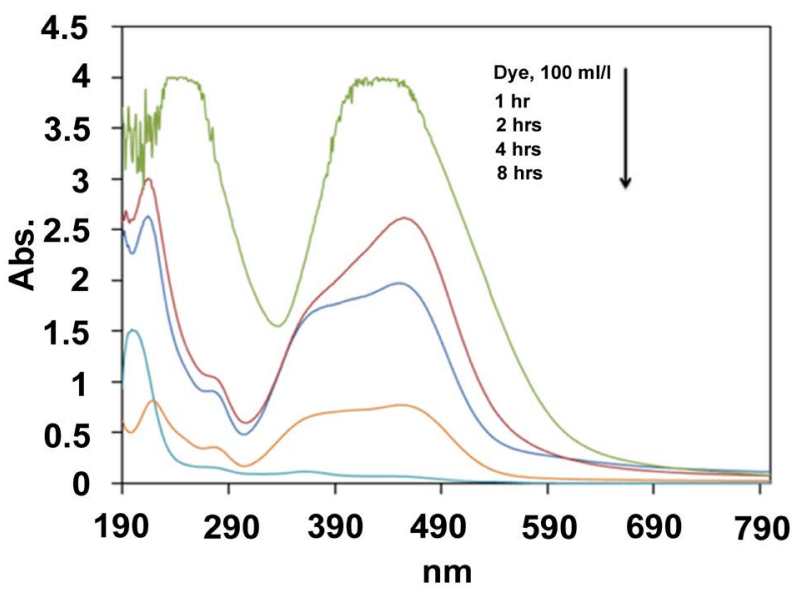

(b)

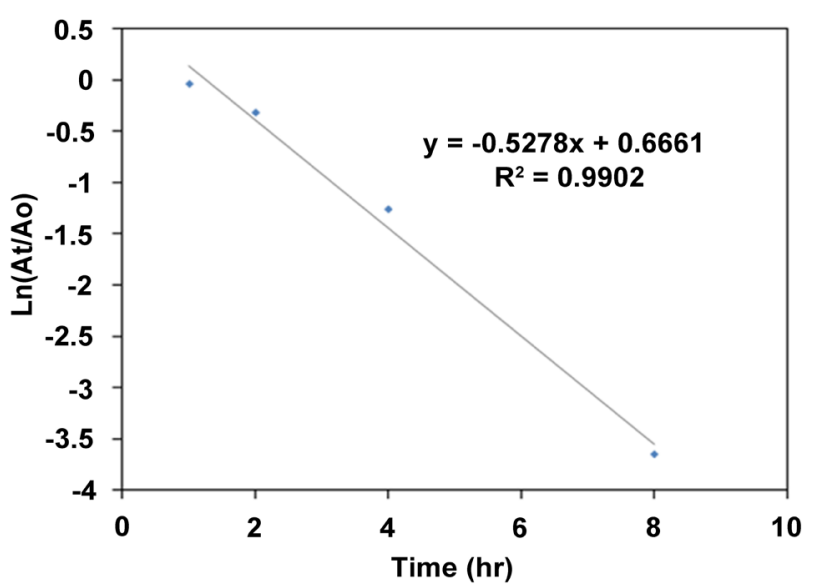

(c)

Figure 8. UV-Vis. spectra of degradation of BB 1 by prepared AgNPs (d), (a) at different doses of AGNPs, (b) with 0.5 ml of AgNPs (d) after $8 \mathrm{~h}$ in direct sun-light and (c) plot of $\ln (A t / A O)$ versus time for the catalytic degradation of basic brown 1. 
Figure 8(b) shows the photocatalytic degradation of $\mathrm{BB} 1$ with $5 \mathrm{ml}$ of green-prepared AgNPs ( $\mathrm{d} \mathrm{Mw}$ ) up to $8 \mathrm{~h}$. The characteristic absorption peak of basic brown 1 dye solution was found to be $462 \mathrm{~nm}$. The colour of the solution changed from brown, yellow, to colorless within $8 \mathrm{~h}$. During the degradation reaction, a gradual decrease in peak intensity at $462 \mathrm{~nm}$ was observed. The characteristic peak of SPR for silver nanoparticles was not seen in the UV-visible spectra in the catalytic degradation investigation. Figure 8(c) represents the plot of $\ln (A t / A o)$ vs. time. The degradation reaction of the basic brown 1 dye was classified as a pseudo-first order reaction. The rate constant $(\mathrm{K})$ was calculated from the plot of $\ln (A t / A 0)$ vs. time, $\mathrm{K}=0.52 \mathrm{~min}^{-1}$.

\section{Conclusion}

From the outcomes of this study, we can conclude that silver nano-particles can be prepared using an aqueous extract of bay leaf. The stability of biosynthetic silver nanoparticles was monitored for up to six months. The prepared AgNPs showed antimicrobial activity against and it increased with increasing the dose of plant extract. The prepared AgNPs showed a high potential to degrade BB1 in aqueous media.

\section{Acknowledgements}

Thanks to the help of Deanship of Scientific Research at Al-Baha University, KSA. This work was financial supported by Deanship of Scientific Research at Al-Baha University, Kingdome of Saudi Arabian (48/1438).

\section{Conflicts of Interest}

The author declares that they have no competing interests.

\section{References}

[1] Abdel-Mohsen, A.M., Hrdina, R., Burgert, L., Krylová, G., Abdel-Rahman, R.M., Krejčová, A. and Beneš, L. (2012) Green Synthesis of Hyaluronan Fibers with Silver Nanoparticles. Carbohydrate Polymers, 89, 411-422. https://doi.org/10.1016/j.carbpol.2012.03.022

[2] Kumar, D.A., Palanichamy, V. and Roopan, S.M. (2014) Green Synthesis of Silver Nanoparticles Using Alternanthera dentata Leaf Extract at Room Temperature and Their Antimicrobial Activity. Spectrochimica Acta Part A: Molecular and Biomolecular Spectroscopy, 127, 68-171. https://doi.org/10.1016/j.saa.2014.02.058

[3] El-Gammal, O.A. (2010) Synthesis, Characterization, Molecular Modeling and Antimicrobial Activity of

2-(2-(Ethylcarbamothioyl)Hydrazinyl)-2-oxo-N-Phenylacetamide Copper Complexes. Spectrochimica Acta Part A: Molecular and Biomolecular Spectroscopy, 75, 533-542. https://doi.org/10.1016/j.saa.2009.11.007

[4] Sana, S.S., Badineni, V.R., Arla, S.K. and Boya, V.K.N. (2015) Eco-Friendly Synthesis of Silver Nanoparticles Using Leaf Extract of Grewia flaviscences and Study of Their Antimicrobial Activity. Materials Letters, 145, 347-350.

https://doi.org/10.1016/j.matlet.2015.01.096 
[5] Gavade, N.L., Kadam, A.N., Suwarnkar, M.B., Ghodake, V.P. and Garadkar, K.M. (2015) Biogenic Synthesis of Multi-Applicative Silver Nanoparticles by Using Ziziphus Jujuba Leaf Extract. Spectrochimica Acta Part A: Molecular and Biomolecular Spectroscopy, 136, 953-960. https://doi.org/10.1016/j.saa.2014.09.118

[6] Eyaane Meva, F., Segnou, M.L., Ebongue, C.O., Ntoumba, A.A., Kedi, P.B.E., Deli, V. and Mpondo, E.M. (2016) Spectroscopic Synthetic Optimizations Monitoring of Silver Nanoparticles Formation from Megaphrynium macrostachyum Leaf Extract. Revista Brasileira de Farmacognosia, 26, 640-646.

https://doi.org/10.1016/j.bjp.2016.06.002

[7] Zuas, O., Hamim, N. and Sampora, Y. (1014) Bio-Synthesis of Silver Nanoparticles Using Water Extract of Myrmecodia pendan (Sarang Semut Plant). Materials Letters, 123, 156-159. https://doi.org/10.1016/j.matlet.2014.03.026

[8] Velusamy, P., Das, J., Pachaiappan, R., Vaseeharan, B. and Pandian, K. (2015) Greener Approach for Synthesis of Antibacterial Silver Nanoparticles Using Aqueous Solution of Neem Gum (Azadirachta indica L). Industrial Crops and Products, 66, 103-109. https://doi.org/10.1016/j.indcrop.2014.12.042

[9] Phull, A.R., Abbas, Q., Ali, A., Raza, H., Zia, M. and Haq, I.U. (2016) Antioxidant, Cytotoxic and Antimicrobial Activities of Green Synthesized Silver Nanoparticles from Crude Extract of Bergenia ciliata. Future Journal of Pharmaceutical Sciences, 2, 31-36. https://doi.org/10.1016/j.fjps.2016.03.001

[10] Vasquez, R.D., Apostol, J.G., de Leon, J.D., Mariano, J.D., Mirhan, C.M.C., Pangan, S.S. and Zamora, E.T. (2016) Polysaccharide-Mediated Green Synthesis of Silver Nanoparticles from Sargassum siliquosum JG Agardh: Assessment of Toxicity and Hepatoprotective Activity. OpenNano, 1, 16-24. https://doi.org/10.1016/j.onano.2016.03.001

[11] Pourmortazavi, S.M., Taghdiri, M., Makari, V. and Rahimi-Nasrabadi, M. (2015) Procedure Optimization for Green Synthesis of Silver Nanoparticles by Aqueous Extract of Eucalyptus oleosa. Spectrochimica Acta Part A: Molecular and Biomolecular Spectroscopy, 136, 1249-1254. https://doi.org/10.1016/j.saa.2014.10.010

[12] Baker, S., Kumar, K.M., Santosh, P., Rakshith, D. and Satish, S. (2015) Extracellular Synthesis of Silver Nanoparticles by Novel Pseudomonas veronii AS41G Inhabiting Annona squamosa L. and Their Bactericidal Activity. Spectrochimica Acta Part A: Molecular and Biomolecular Spectroscopy, 136, 1434-1440.

https://doi.org/10.1016/j.saa.2014.10.033

[13] Sadeghi, B., Rostami, A. and Momeni, S.S. (2015) Facile Green Synthesis of Silver Nanoparticles Using Seed Aqueous Extract of Pistacia atlantica and Its Antibacterial Activity. Spectrochimica Acta Part A: Molecular and Biomolecular Spectroscopy, 34, 326-332. https://doi.org/10.1016/j.saa.2014.05.078

[14] Rajeshkumar, S. (2016) Synthesis of Silver Nanoparticles Using Fresh Bark of Pongamia pinnata and Characterization of Its Antibacterial Activity against Gram Positive and Gram Negative Pathogens. Resource-Efficient Technologies, 2, 30-35. https://doi.org/10.1016/j.reffit.2016.06.003

[15] Anand, B.G., Thomas, C.K.N., Prakash, S. and Kumar, C. (2015) Biosynthesis of Silver Nano-Particles by Marine Sediment Fungi for a Dose Dependent Cytotoxicity against HEp2 Cell Lines. Biocatalysis and Agricultural Biotechnology, 4, 150-157. https://doi.org/10.1016/j.bcab.2015.01.002

[16] Velayutham, K. and Ramanibai, R. (2016) Larvicidal Activity of Synthesized Silver Nanoparticles Using Isoamyl Acetate Identified in Annona squamosa Leaves against Aedes aegypti and Culex quinquefasciatus. The Journal of Basic \& Applied Zoology, 
74, 16-22. https://doi.org/10.1016/j.jobaz.2016.02.002

[17] Mohammed, A.E. (2015) Green Synthesis, Antimicrobial and Cytotoxic Effects of Silver Nanoparticles Mediated by Eucalyptus camaldulensis Leaf Extract. Asian Pacific Journal of Tropical Biomedicine, 5, 382-386. https://doi.org/10.1016/S2221-1691(15)30373-7

[18] Reddy, T.R.K. and Kim, H.-J. (2016) Facile Synthesis of Silver Nanoparticles and Its Antibacterial Activity against Escherichia coli and Unknown Bacteria on Mobile Phone Touch Surfaces/Computer Keyboards. Applied Physics A, 122, 652. https://doi.org/10.1007/s00339-016-0193-6

[19] Muthukumaran, U., Govindarajan, M. and Rajeswary, M. (2015) Mosquito Larvicidal Potential of Silver Nanoparticles Synthesized Using Chomelia asiatica (Rubiaceae) against Anopheles stephensi, Aedes aegypti, and Culex quinquefasciatus (Diptera: Culicidae). Parasitology Research, 114, 989-999.

https://doi.org/10.1007/s00436-014-4265-2

[20] Khan, M.N., Khan, T.A., Khan, Z. and AL-Thabaiti, S.A. (2015) Green Synthesis of Biogenic Silver Nanomaterials Using Raphanus sativus Extract, Effects of Stabilizers on the Morphology, and Their Antimicrobial Activities. Bioprocess and Biosystems Engineering, 38, 2397-2416. https://doi.org/10.1007/s00449-015-1477-5

[21] Parlinska-Wojtan, M., Kus-Liskiewicz, M., Depciuch, J. and Sadik, O. (2016) Green Synthesis and Antibacterial Effects of Aqueous Colloidal Solutions of Silver Nanoparticles Using Camomile Terpenoids as a Combined Reducing and Capping Agent. Bioprocess and Biosystems Engineering, 39, 1213-1223. https://doi.org/10.1007/s00449-016-1599-4

[22] Venugobal, J. and Anandalakshmi, K. (2016) Green Synthesis of Silver Nanoparticles Using Commiphora caudata Leaves Extract and the Study of Bactericidal Efficiency. Journal of Cluster Science, 27, 1683-1699. https://doi.org/10.1007/s10876-016-1032-9

[23] Amin, Z.R., Khashyarmanesh, Z. and Bazzaz, B.S.F. (2016) Different Behavior of Staphylococcus epidermidis in Intracellular Biosynthesis of Silver and Cadmium Sulfide Nanoparticles: More Stability and Lower Toxicity of Extracted Nanoparticles. World Journal of Microbiology and Biotechnology, 32, 140.

[24] Zhang, W., Zhang, L. and Sun, Y. (2015) Size-Controlled Green Synthesis of Silver Nanoparticles Assisted by L-Cysteine. Frontiers of Chemical Science and Engineering, 9, 494-500. https://doi.org/10.1007/s11705-015-1527-1

[25] Otari, S.V., Patil, R.M., Ghosh, S.J. and Pawar, S.H. (2014) Green Phytosynthesis of Silver Nanoparticles Using Aqueous Extract of Manilkara zapota (L.) Seeds and Its Inhibitory Action against Candida Species. Materials Letters, 116, 367-369. https://doi.org/10.1016/j.matlet.2013.11.066

[26] Otari, S.V., Pawar, S.H., Patel, S.K., Singh, R.K., Kim, S.Y., Lee, J.H., et al. (2017) Canna edulis Leaf Extract-Mediated Preparation of Stabilized Silver Nanoparticles: Characterization, Antimicrobial Activity, and Toxicity Studies. Journal of Microbiology and Biotechnology, 27, 731-738. https://doi.org/10.4014/jmb.1610.10019

[27] Alsammarraie, F.K., Wang, W., Zhou, P., Mustapha, A. and Lin, M. (2018) Green Synthesis of Silver Nanoparticles Using Turmeric Extracts and Investigation of Their Antibacterial Activities. Colloids and Surfaces B: Biointerfaces, 171, 398-405. https://doi.org/10.1016/j.colsurfb.2018.07.059

[28] Moghtader, M. and Salari, H. (2010) Comparative Survey on the Essential Oil Composition from the Leaves and Flowers of Laurus nobilis L from Kerman Province. Journal of Ecology and the Natural Environment, 4, 150-153. 
[29] Verdian-rizi, M. (2009) Variation in the Essential Oil Composition of Laurus nobilis $\mathrm{L}$ of Different Growth Stages Cultivated in Iran. Journal of Basic and Applied Sciences, 5, 33-36.

[30] Özek, T. (2012) Distillation Parameters for Pilot Plant Production of Laurus nobilis Essential Oil. Records of Natural Products, 6.

[31] Moghtader, M. and Salari, H. (2012) Comparative Survey on the Essential Oil Composition from the Leaves and Flowers of Laurus nobilis L. from Kerman Province. Journal of Ecology and the Natural Environment, 4, 150-153.

[32] Das, J., Paul Das, M. and Velusamy, P. (2013) Sesbania grandiflora Leaf Extract Mediated Green Synthesis of Antibacterial Silver Nanoparticles against Selected $\mathrm{Hu}$ man Pathogens. Spectrochimica Acta Part A: Molecular and Biomolecular Spectroscopy, 104, 265-270. https://doi.org/10.1016/j.saa.2012.11.075

[33] Ibrahim, H.M. (2015) Green Synthesis and Characterization of Silver Nanoparticles Using Banana Peel Extract and Their Antimicrobial Activity against Representative Microorganisms. Journal of Radiation Research and Applied Sciences, 8, 265-275. https://doi.org/10.1016/j.jrras.2015.01.007

[34] de Matos, R.A. and Courrol, L.C. (2014) Saliva and Light as Templates for the Green Synthesis of Silver Nanoparticles. Colloids and Surfaces A: Physicochemical and Engineering Aspects, 441, 539-543. https://doi.org/10.1016/j.colsurfa.2013.10.009

[35] Tang, Y.J., Ashcroft, J.M., Chen, D., Min, G., Kim, C.H., Murkhejee, B. and Chen, F.F. (2007) Charge-Associated Effects of Fullerene Derivatives on Microbial Structural Integrity and Central Metabolism. Nano Letters, 7, 754-760. https://doi.org/10.1021/nl063020t

[36] Neal, A.L. (2008) What Can Be Inferred from Bacterium-Nanoparticle Interactions about the Potential Consequences of Environmental Exposure to Nanoparticles? Ecotoxicology, 17, 362. https://doi.org/10.1007/s10646-008-0217-x

[37] Wang, Y., Huang, F., Pan, D., Li, B., Chen, D., Lin, W. and Lin, Z. (2009) Ultraviolet-Light-Induced Bactericidal Mechanism on ZnO Single Crystals. Chemical Communications, No. 44, 6783-6785. https://doi.org/10.1039/b912137d

[38] Sau, T.K. and Rogach, A.L. (2010) Nonspherical Noble Metal Nanoparticles: Colloid-Chemical Synthesis and Morphology Control. Advanced Materials, 22, 1781-1804. https://doi.org/10.1002/adma.200901271

[39] Tai, Y.L. and Yang, Z.G. (2011) Fabrication of Paper-Based Conductive Patterns for Flexible Electronics by Direct-Writing. Journal of Materials Chemistry, 21, 5938-5943. https://doi.org/10.1039/c0jm03065a

[40] Kim, J.S., Eunye, K., Yu, K.N., Kim, J.H., Park, S.J., Lee, H.J., Kim, S.H., Park, Y.K., Park, Y.H., Wang, C.Y., Kim, Y.K., Lee, Y.S., Jeong, D.H. and Cho, M.H. (2007) Antimicrobial Effects of Silver Nanoparticles. Nanomedicine: Nanotechnology, Biology and Medicine, 3, 95-101. https://doi.org/10.1016/j.nano.2006.12.001

[41] Kim, S.H., Lee, H.S., Ryu, D.S., Choi, S.J. and Lee, D.S. (2011) Antibacterial Activity of Silver-Nanoparticles against Staphylococcus aureus and Escherichia coli. Journal of Microbiology and Biotechnology, 39, 77-85. 